ISSN 1991- 8690

Website: http://jsci.utq.edu.iq

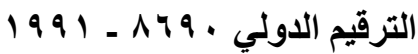

الدور الواقي للكبد للخلاصة المائية للزنجبيل ضد التأثيرات الضارة للبراسيتامول في الجرذان

Email: utjsci@utq.edu.iq

\author{
جميلة كاظم عبد الحسن \\ كلية طب الاسنان - جامعة القادسية
}

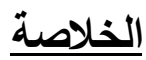

أجريت هذه الدراسة لغرض تقيبم التأثيرات الواقية للكبد التي تعطيها الخلاصة المائية للزنجبيلZingiberofficinale بعد استحداث تسمم الكبد الحاد

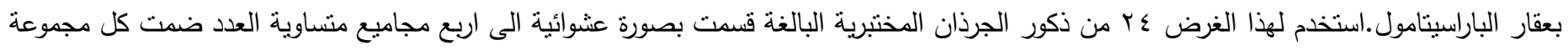
1 جرذان ، الججموعة الاولى : عدت كسيطرة سالبة اعطيت المحلول الفسلجي فقط ، المجموعة الثانية تمثلت سيطرة موجبة اعطيت عقار البارسيتامول

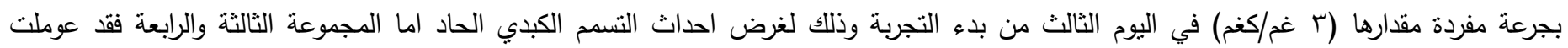

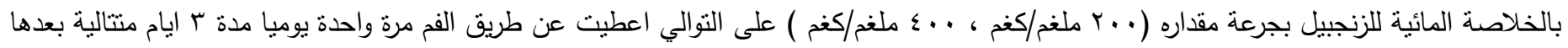

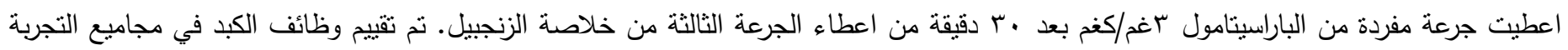

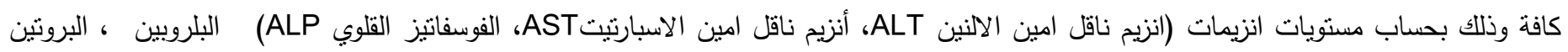

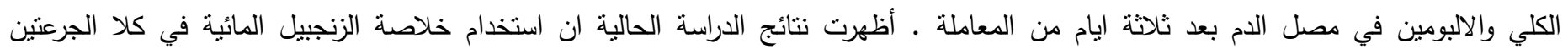
المستخدمتين في هذه الدراسة قد ادت الى انخفاض معنوي في انزيمات الكبد وبلروبين المصل الكلي في حين ادت الى زيادة معنوية في مستويات بروتين

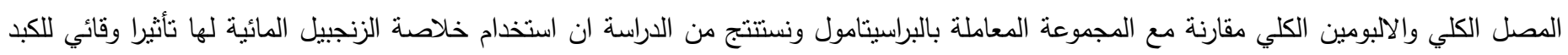
من الحالات السمية المحدثة بالبراسيتامول وذلك من خلال تحسين بعض المعايير الكيميوحيوية وارجاعها الى المستويات الطبيعية. الكلمات الافتتاحية : المستخلص المائي للزنجبيل ، البراسيتامول ، الجرذان

\title{
The hepatoprotective role of the aqueous extract of ginger against the harmful effects of paracetamol in rats
}

\author{
Jameela KadhimAbd-ALHassan
}

\begin{abstract}
This study was performed to determine the hepatoprotectiveactivities of watery extract of ginger in hepatotoxicity induced by paracetamolin albino rats. Twenty fourrats were used and divided randomly into four equal groups each of which contain six animals, the first one was served as control, received nomal saline only, the second group were received paracetamol at a single dose of $3 \mathrm{~g} / \mathrm{kg} / \mathrm{B}$.W orally to induce hepatotoxicity, and the third and fourth groups received watery extract of ginger at a dose $200 \mathrm{mg} / \mathrm{Kg} \& 400 \mathrm{mg} / \mathrm{Kg} \mathrm{B}$.W orally once daily for 3 days respectively followed by administration of single dose of paracetamol $3 \mathrm{~g} / \mathrm{Kg}$ B.Wafter 30 minute after extracts administration. Liver functions were assessed by estimating serumalanine amino transferase (ALT), aspartate amino transferase (AST), alkaline phosphatase (ALP), total serum bilirubin \& total serum protein $\&$ albumin . The results revealed that the use of genger extracts at each dose ( $200 \mathrm{mg} / \mathrm{Kg}, 400 \mathrm{mg} / \mathrm{Kg}$ B.W) produced significant reduction in the level of these enzymes, total bilirubin while caused significant increase in the levels of total serum protein \& total serum albumin ,
\end{abstract}

College of dentistry -Al-Qadissyia University 
so the use of ginger extracts possess hepatoprotective activity by restoring the normal hepatic functions and potentiating the bio- defense system of the liver against hepatotoxicity produced by paracetamol administration .

Key words: watery extract of ginger, paracetamol, rats

للسرطان (10)، الفعل المضاد للاكسدة (19)، الفعل المضاد للالتهاب المقدمة

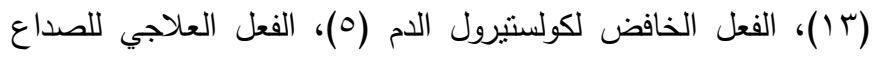

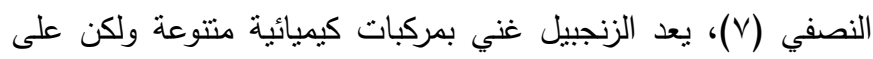

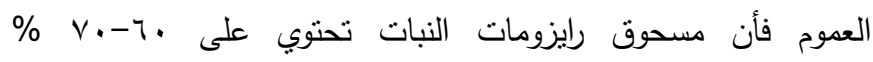

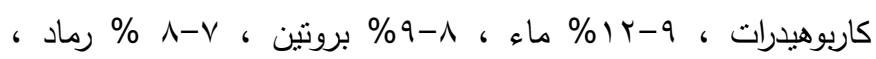

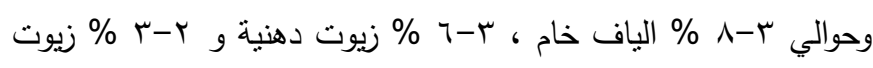

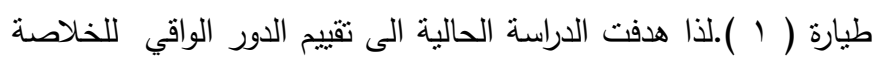

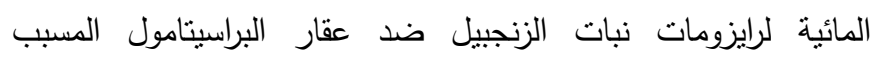
للتأثيرات السامة للكبد في الجرذان المختبرية. طرائق العمل مصدر التبات تم الحصول على رايزومات نبات الزنجبيل من الاسواق المحلية

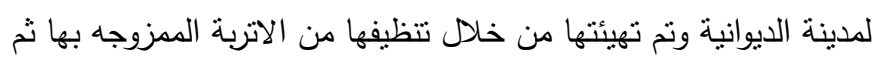

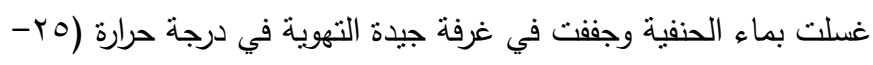

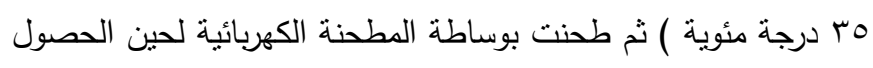

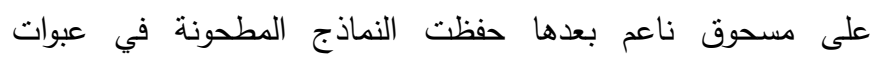
بلاستيكيةمعلمة لحين اجراء عملية الاستخلاص عليها. تحضير الخلاصة المائية لنبات الزنجيلي

تم اعتماد الطريقة المذكورة من قبل ( r )في تحضير الخلاصة

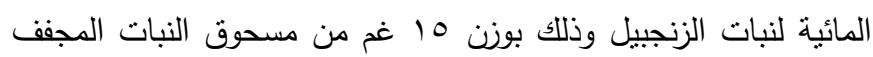

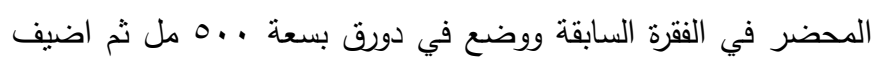

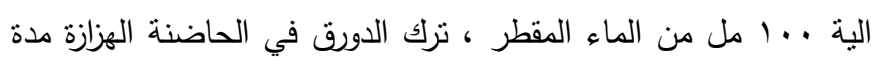

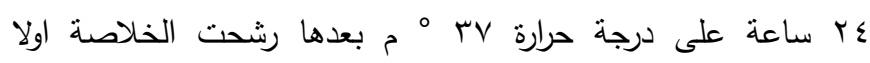

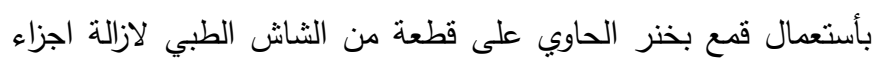

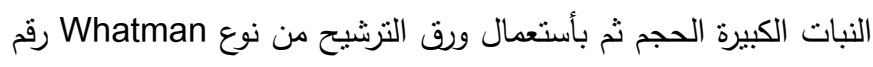

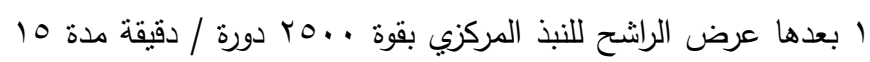

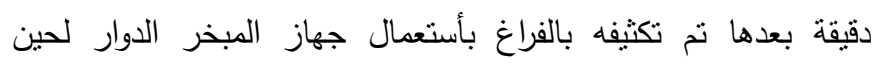

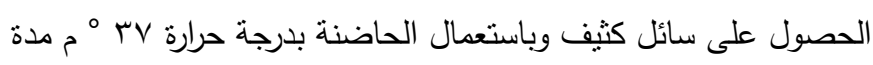

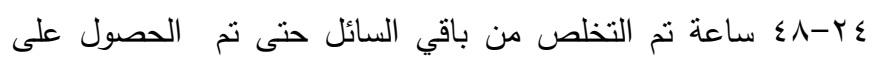

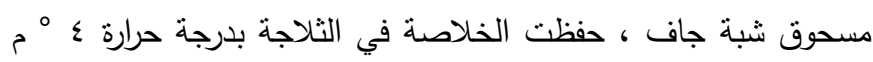

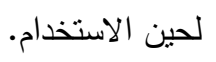


المصل بمساعدة جهاز الطرد المركزي ... الم دورة / بالدقيقة مدة 10

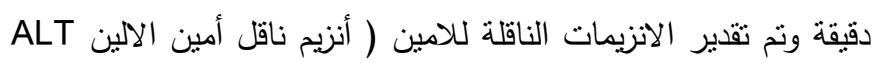

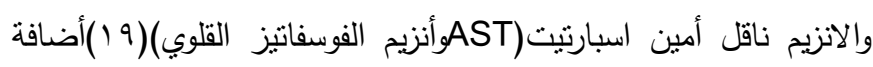
الى تقدير مسنوى بلروبين المصل الكلي (ع ()وبروتين المصل الكلي الكئي

والالبومين( (1) ).

التحليل الاحصائي أخضعت نتائج الدراسة للتحليل الاحصائي اذ تم التعبير عن النتائج بالمعدل \pm الخطأ القياسي واجريت عمليات نحليل النتائج بأستخدام اختبار ANOVA مع أقل فرق معنوي LSD وتحت مستوى احتمالية

\section{النتائج والمناقشية}

اظهرت نتائج الدراسة المدونة في جدول (1)ان نسب مسنويات

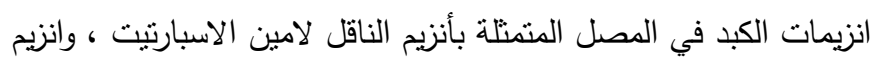

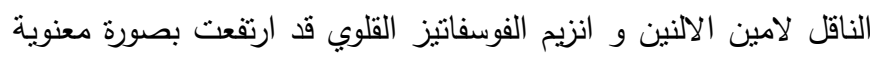

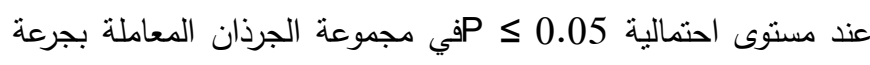

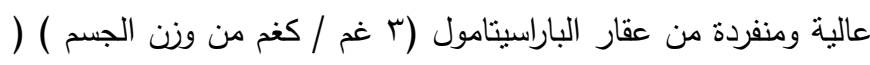
( $)$ ( وحدة / لتز

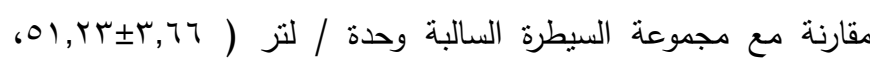

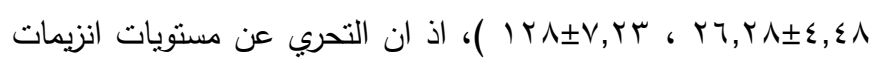

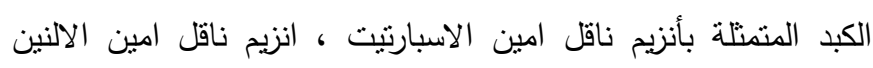

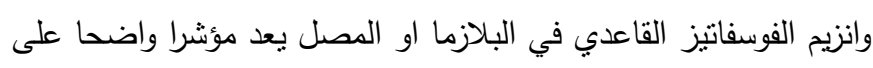
الاداء الوظيفي للكبد حيث ان فقدان سلامة الغثاء السايتوبلازمي للخلايا

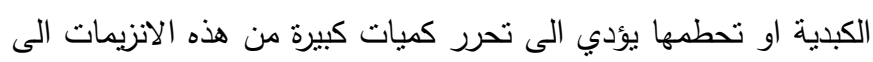
مجرى الدم (7 1 ) ان ارتفاع مستوى هذه الانزيمات في مجموعة الجرذان

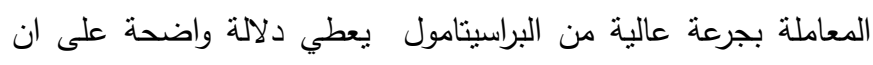

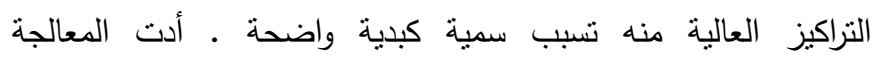

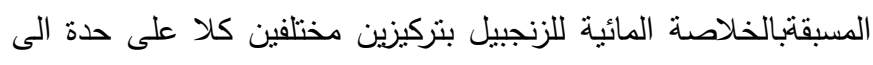

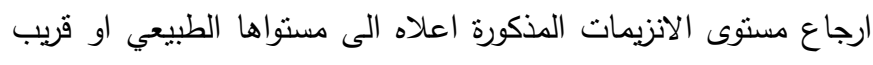

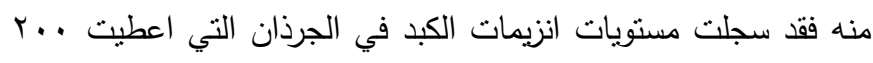

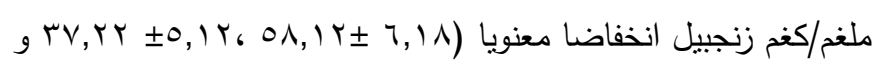

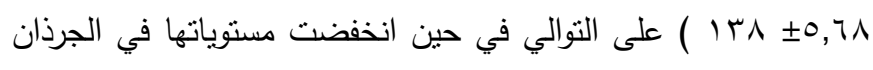

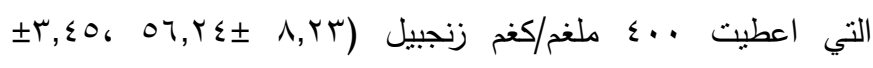

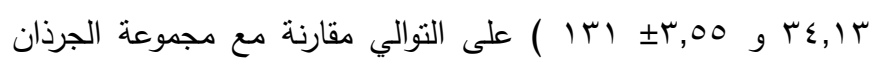
التي عوملت بعقار البراسيتامول وحده.ان القدرة التصحيحية للادوية او التئية

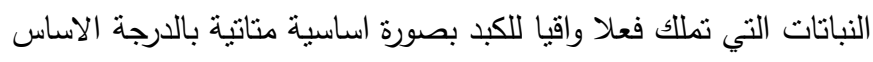

\section{حيوانات التجربية}

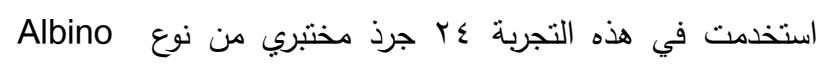
(rats(Rattusnorvegicus

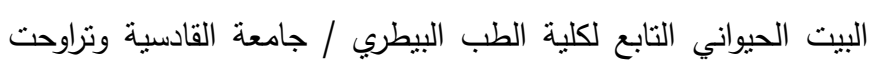

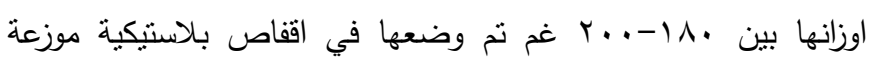

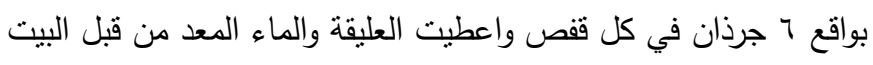

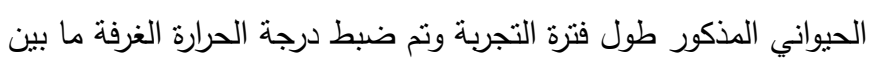

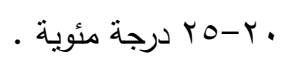

تصميم التجرية استخدم البراسيتامول كنموذج لاستحداث الضرر الكبدي وقنمت

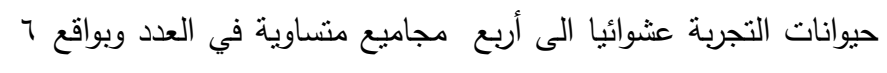
جرذان لكل مجموعة وقد عوملت الحيوانات على النحو التالي :

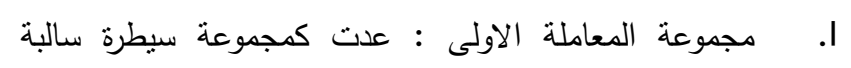

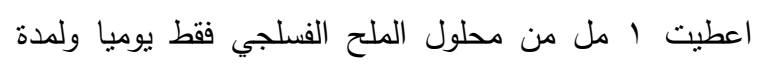
ثلاثة ايام متتالية. II. مجموعة المعاملة الثانية : عدت كمجموعة سبطرة موجبة

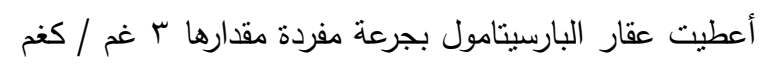

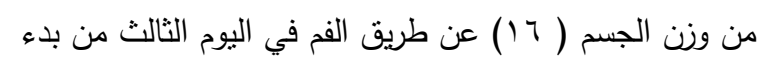
التجربة من وزن الت

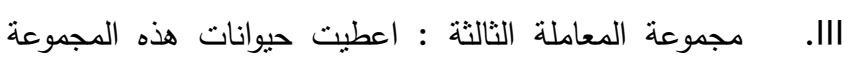

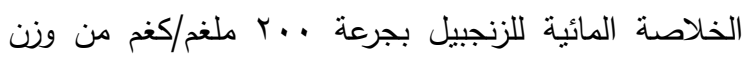
الجسم عن طريق الفم مرة واحدة يوميا مدة ب ايام منتالية

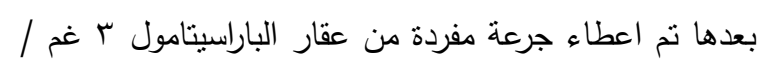

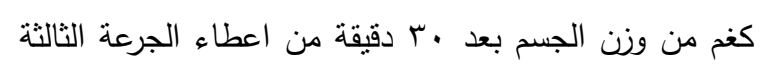

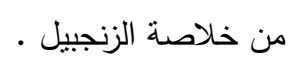
مجموعة المعاملة الرابعة : اعطيت حيوانات هذه المجموعة .IV

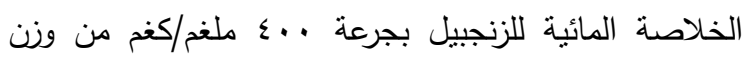

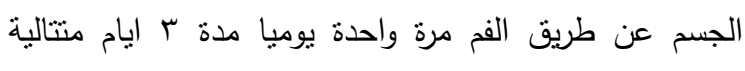

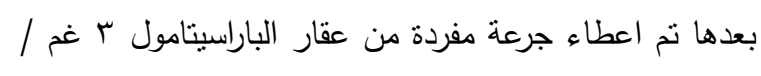
كغم من وزن الجسم بعد .ب دقيقة من اعطاء الجرعة الثالثة

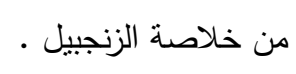
تقدير الضرد الكبدي بعد من VY ساعة من اعطاء المعاملات التي تضدنتها الدراسة نم جمع

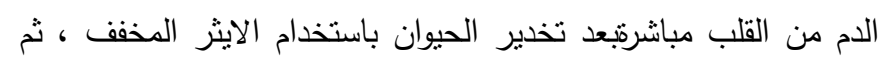

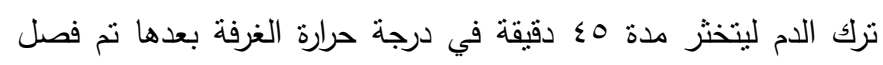


ملغم ثلاث مرات اسبوعيا ولمدة 7 اسابيع منتاية عن طريق الفم في الفي

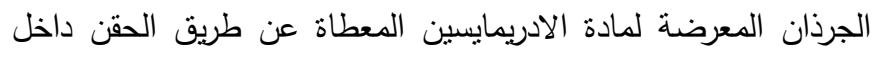

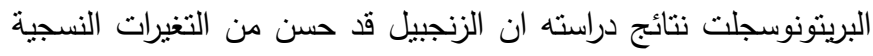

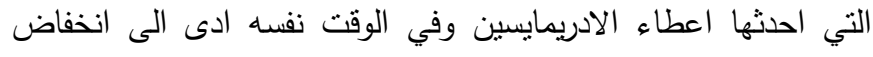

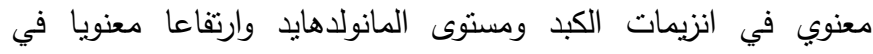
السوبراوكسايد دسميوتيس وقد اعزى ذللك للفعالية المضادة للاكسدة لمستخلص الزنجبيل.كما درس (r)/الدور الايجابي للخلاصة المائية

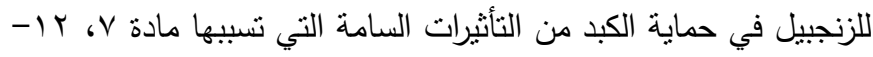
dimethylbenz(a)anthracene (DMBA خلال كبح الاوكسجين الحر وجذور النايتروجين المتكونة بالكبد بفعل

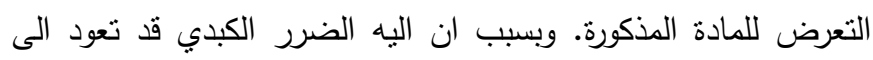

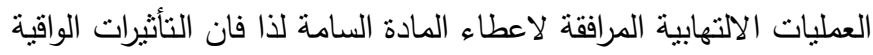

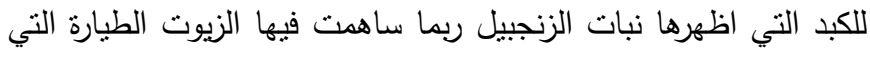

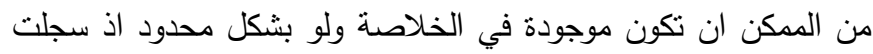

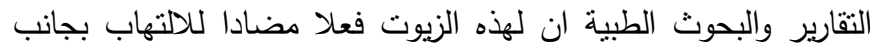

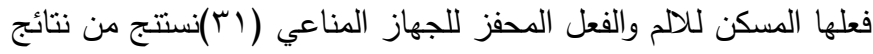

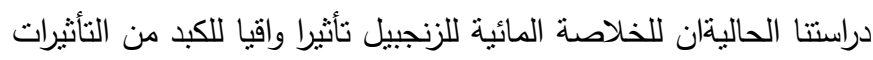
السامة التي ييديها البراسيتامول في الجرذان المختبرية. جدول (1) تأثير الخلاصة المائية للزنجبيل على مستوبات انزبمات الكبد في ذكور الجرذان المختبرية المعاملة بالباراسيتامول

\begin{tabular}{|c|c|c|c|}
\hline \multicolumn{3}{|c|}{ 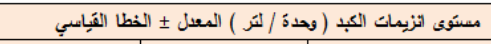 } & \multirow[t]{2}{*}{ نوع المعاملة } \\
\hline $\begin{array}{c}\text { أنزيم الفوسفاتيز } \\
\text { القموي } \\
\text { ALP }\end{array}$ & $\begin{array}{c}\text { أنزيم نامكل امين } \\
\text { الالثنين } \\
\text { ALT }\end{array}$ & 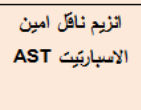 & \\
\hline $\begin{array}{c}128 \pm 7.23 \\
\text { A }\end{array}$ & $\begin{array}{c}26.28 \pm 4.48 \\
\text { A }\end{array}$ & $\begin{array}{l}51.23 \pm 3.66 \\
\text { A }\end{array}$ & $\begin{array}{c}\text { الصبطرة السبالبة (المحلول الملحي } \\
\text { الفسلجب ) }\end{array}$ \\
\hline $\begin{array}{c}287 \pm 12.24 \\
\text { B }\end{array}$ & $\begin{array}{c}159.68 \pm 6.34 \\
\text { B }\end{array}$ & $\begin{array}{l}167.34 \pm 7.43 \\
\text { B }\end{array}$ & المبطرة الموجبة (الجارسبيّامول غم/كفم 3 \\
\hline $\begin{array}{c}138 \pm 5.68 \\
\text { A }\end{array}$ & $\begin{array}{c}37.22 \pm 5.12 \\
\text { A }\end{array}$ & $\begin{array}{l}58.12 \pm 6.18 \\
\text { A }\end{array}$ & الخلاصة المائبة للزنجبيل (200 ملفم/ كفم) \\
\hline $\begin{array}{c}131 \pm 3.55 \\
\text { A }\end{array}$ & $\begin{array}{c}34.13 \pm 3.45 \\
\text { A }\end{array}$ & $\begin{array}{l}56.34 \pm 8.23 \\
\text { A }\end{array}$ & الخلاصة المائية للزنجبيل (400 ملفم/كفم) \\
\hline
\end{tabular}

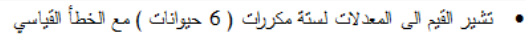

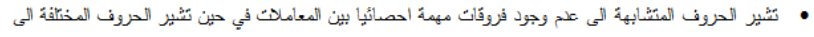

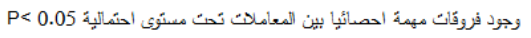

من خلال القدرة على تقليل التأثيرات الضارة التي تسببها المادة السامة للكبد او من خلا المحافظة على الالية الوظيفية الطبيعية للخلايا الكبدية التي نتغيير بفعل التعرض الى المادة السامة للكبد ( V ) وهذا يعود في الغالب الى ان المكونات الطبية الفعالة الموجودة في نبات الزنجبيل قد لعبت دورا حيويا في المحافظة على السلامة التركيبية للغشاء السايتوبلازمي للخلايا الكبدية ، ومن اهم هذه المركبات هي بـان gingerol كما اظهرت نتائج الدراسة المدونة في جدول (Y) ان نسب مستويات البروتين الكلي والالبومين الكلي قد انخفضت معنويا تحت مستوى احتمالية 0.05 S في مجموعة الجرذان المعاملة بجرعة عالية ومنفردة من عقار البراسيتامول وسجلت مستوياتها ( ( (

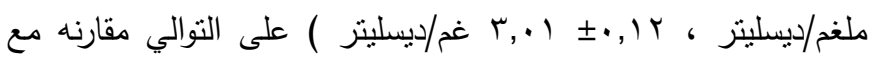

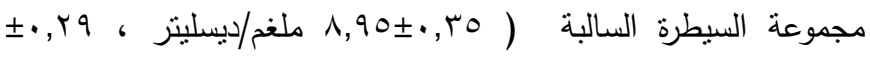
7 • , ا غم/ديسليتر ) على التوالي في حين ارتفع مستوى البلروبين الكلي

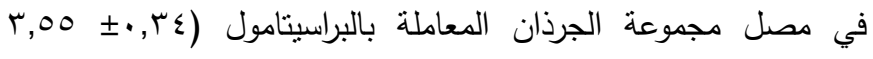

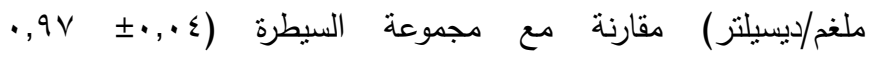
ملغم/ديسيلتر).اذ ان مستويات البروتين الكلي والالبومين والبلروبين هي هي الاخرى ترنبط ارتباطا وثيقا مع وظيفة الخلايا الكبدية وهي تكثف وبشكل واضح الحالة الوظيفية للخلايا الكبدية وبالنتيجة عمل الكبد بصورة عامة اذ ان انخفاض مستويات البروتين الكلي والالبومين الكلي في المصل يعد مؤشرا على فثل الوظيفة التصنيعية للخلايا الكبدية في حين ان زيادة مستوى البلروبين الكلي في المصل يعد مؤثرا الى الخلل في الاخذ

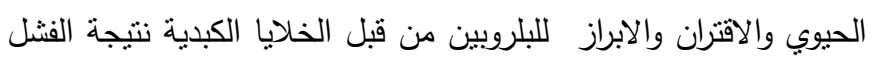
الوظيفي الذي اصاب الخلايا الكبدية( مب)ادى الاعطاء المسبق للخلاصة المائية للزنجبيل وبتركيزين مختلفين كلا على حدة الى ارتفاع مستوى البروتين الكلي والالبومين ورجوعها الى مستويات قريبة من

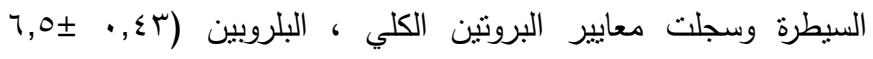
، ع, •  وخفض مستوى البلروبين ورجوعه الى مستوى قربب من السيطرة عند

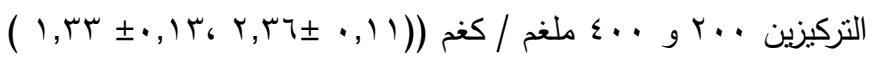
ملغم / ديسيلتز على التوالي ، نتائج دراستتا عززت دراسات سابقة اجريت في هذا الصدد على مستخلصات مختلفة محضرة من اجزاء مختلفة من في نبات الزنجبيل ففي الاراسة التي قام بها (Yr) والتي فحص الفعالية الواقية للكبد للخلاصة المائية لرايزومات الزنجبيل والمعطاة بواقع عالهي 


\section{References}

المصادر

1. Ali, B.H.;

Nemmar,A.Some

Blunder,G.;Tanira,M.O.and Phytochemical, pharmacological and toxicological properties of Ginger (Zinigberofficinale Roscoe): a review of recent research.

Food Chem.Toxicol.2008.46:409-420.

2. Ali,D.A.; Ismail, M.F. and Badr, H.A.Hepatoprotective effect of ginger extract against the toxicity of 7, 12-dimethylbenz (a)anthracene (DMBA) in albino rats.J.of Pharmaceut.Sci.2013.1:61-71.

3. Anessini,C. and Perez,C.Screening of plant used for Argentina folk medicine for antimicrobial activity .J.Ethropharmacol.1993.39:119-128.

4. Awadh,A.;Juelich,W.;Kusunick;C. and Lindequist,U.Screening of Yemeni medicinal plants for antibacterial and cytotoxic activities.J.Ethnopharmacol.2001.74:173-179.

5. Bhandari,U.; Kanojia,R. and Pillai,K.Effects of ethanolic extract of Zingiberofficinaleon dyslipidaemia .J.Ethnopharmacol.2005.97:227230.

6. Borrelli,F. ; Capasso,R. and Pint,A.Inhibition effect of ginger on rat ileal motility in vitro.Life Sci.2004.44:2889-2896.

7. Cady, R. ;Schreihen,C. ;Beach,M. \&hart,C.Gelstalmigrainew for acute treatment of migraine when administered during the mild pain phase.Med.Sci.Monit.2005.11:165-169.

8.El-Faky, F.; Attif,O.; Aboul,M. and Gaanem,N.Antimicrobial activity of some Egyptian spices essential oils.J.Food Prot.1995. 52:665-667. disease.IndianJ. Clin.Biochem. 1999.14:59-65.

9.Ghayur,M. and Gilani,A.Pharmacological basis for the medicinal use of ginger in gastrointestinal disorder.Dig.Dis.Sci.2005.50:1889-2896.

10.Hurkkeri,V.;Jaiprakash,M.S.;Lavhale,R.;Karadi,R. and Kuppast,I.Hepatoprotective activity of AlanthusexcelsaRoxb. Leaf extracts on experimental liver damage in rats.Indian J.pharm.Educ.2002.37:105-106.

11.Kingsley, S.R.\& Frankel S.J.The determination of serum total protein albumin and globulin by the biuret reaction. J. Biol. Chem .1939.128:131-7-.

12.Kiran,P.M.;Raju,A.V. and Rao,B.G.Investigation of hepatoprotective activity of Cyatheagigantea (Wall. ex. Hook.) leaves against paracetamol-

$$
\text { جدول (r) تأثير الخلاصة المائية للزنجبيل على مستويات البيلروبين }
$$

\begin{tabular}{|c|c|c|c|}
\hline \multicolumn{3}{|c|}{ 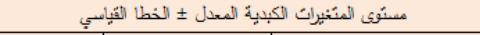 } & \multirow[t]{2}{*}{ نويع المعاملة } \\
\hline (غم/لبيسلبير ) & البيلزروبين الكلبي & الثيروئين الكلي (ملغت/ديسلتر) & \\
\hline $6.06 \pm 0.29$ & $0.97 \pm 0.04$ & $8.95 \pm 0.35$ & المبطرة العسالبة (لالمحلول الملحي الفـلجي ) \\
\hline A & A & A & \\
\hline $3.01 \pm 0.12$ & $3.55 \pm 0.34$ & $6.12 \pm 0.41$ & المبطرة الموجبة (الباربيتًامول 3 غب/كغم \\
\hline B & B & B & \\
\hline $4.18 \pm 0.4$ & $2.36 \pm 0.11$ & $6.5 \pm 0.43$ & الخلاصةّة المائية للزئجبيل (200 ملغخ/ كغخ) \\
\hline $\mathrm{C}$ & c & B & \\
\hline $4.55 \pm 0.35$ & $1.33 \pm 0.13$ & $6.26 \pm 0.22$ & الخلاصة المائية تلزيجبيل (400 ملغن/كنم) \\
\hline $\mathrm{C}$ & A & B & \\
\hline
\end{tabular}

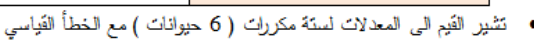

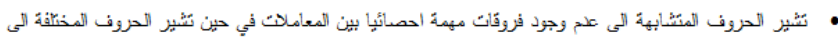

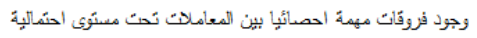

$P<0.05$

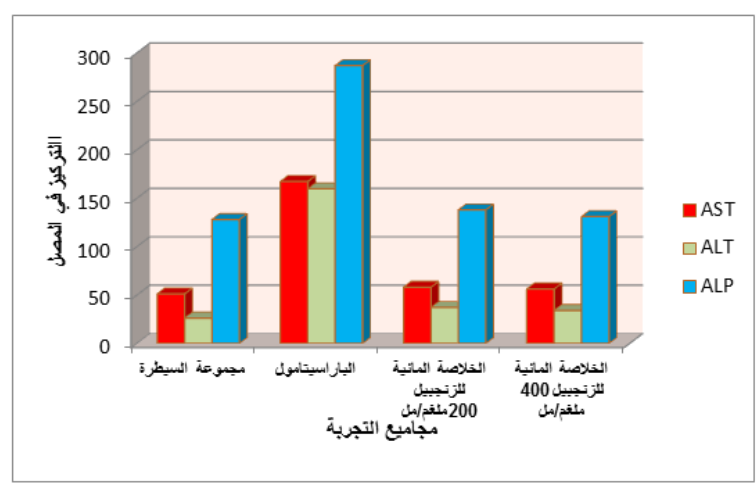

شكل (1) تأثثر الخلاصة المائية للزنجبيل على مستويات انزيمات الكبد في الجرذان المعرضة للباراسيتامول

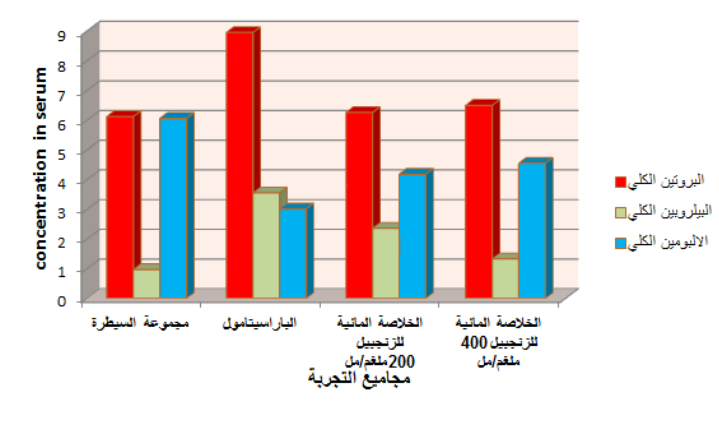

شكل (Y) تأثثر الخلاصة المائية للزنجبيل على مستويات البيلروبين والبروتين الكلي والالبومين في الجرذان المعرضة للباراسيتامول. 
thrombicAgent.Prostagl.Leukotr.Essen.2002.67:4 75-478.

25.Thapa,B. \&Walia,A.Liver function tests \& their interpretation .Indian J. of pediatrics.2007.74:663-671.

26.Ward, F.M. and Daly, M. J.Hepatic Disease. In: Clinical pharmacy and Therapeutics" Churchill livingstone, New York: 1999.195-212

27.Wolf,P.L.Biochemical diagnosis of liver. Indian .Clin.Biochem.14:59-65.

28.Yahaya,O. ;Yabefa,J.A. ; Umar,I.O.; Datshen,M.M. ;Egbunu Z.H.\&Ahmed,J.Combine Antimicrobial Effect of Ginger and Honey on Some Human Pathogens.British J. of Pharm. \& Toxico.2012.3:237-239.

29.Zhang,Z. ; Wang,X. ; Zhang,J. and Zhao,M.Potential antioxidant activities in vitro of polysaccharides extracts from ginger.J. of Carb.Polymers.2011.86:448-45.

30.Zhong, X.I.; Jie,Y.I. and Bao,H.X.6-gingerol, an active ingredient of ginger, protects acetaminophen-induced hepatotoxicity in mice.2011.9:1264-1269.

31.Zhou, H.; Deng ,Y. andXieQ.The modulatory effects of the volatile oil of ginger on the cellularimmune response in vitro and in vivo in mice. Journal of Ethnopharmacology.2006.105: 301-305. induced hepatotoxicity in rats.Asian Pak. J. Trop.Biomed.2012.2:352-356.

13.Mahmoud,M. ; Diaai,A.A. ; Ahmed,F and Ren , F.Evaluation of the efficacy, Arabic gum and boswellia in acute and chronic renal failure .2012.34:73-82 .

14.Mallory H.T and Evelyn, E.A. The determination of bilirubin with photoelectric colorimeter. J .Biol .Chem .1937. 119:481-5.

15.Manju V, Nalini N. Effect of ginger on bacterial enzymes in 1, 2-dimethylhydrazine induced experimental colon carcinogenesis. Eur. J .Cancer Prev .2006.15:377-383.

16.Manokarvan,S.;Jaswanth,A.;Sengotuvelu,S.;Nadhak umar,J.Duraisamy,R.Hepatoprotective activity of Aervalanata against paracetamol induced hepatotoxicity in rats.Res.J.Pharm. and Tech.2008.1:398-400.

17.Raghardran, B.;Sathivel,A. and Devaki,T.Hepatoprotective nature of seaweed alcoholic extract on acetaminophen induced oxidative stress.J . Health Sci.2003.50:42-46.

18.Rani, M. P .;Krishna, M. S.; Padmakumari, K, P .Raghu, K.Zingiberofficinale extracts antidiabetic potential via modulating glucose uptake, protein glycation\& inhibiting adipocyte differentiation:an in vitro study.J.Sci.Food\& Agri.2012.92:1948-1952.

19.Retimen,S and Frankel,S.A.Colorimetric methods for determination ofSerum glutamic oxaloacetic and glutamic pyruvate transamines .Am.J.Clin.Pathol.1957.28:56-63.

20. Schielfer,W.C. Statistics for the biological sciences.2nded.Addison .Wesley publComp,California,London.1980.

21.Shoji,N.;Iwasa,A.;Takemoto,T.;Ishida,Y. and Ohizumi,Y. Cardiotonic principles of ginger (Zinigberofficinale Roscoe).J.pharm. Sci.1982.71:1174-1175.

22.Sokr,S.A.;Mahran,H.A. and Lamfon,H.A.Protective effect of ginger (Zingiberofficinale) onadriamycin - induced hepatotoxicity in albino rats.J. Med.Plants.Res.2011.5:133-140.

23.Tiran,P.(2012).Ginger to reduce nausea and vomiting during pregnancy .Complement ther.Clin.Pract.18:22-25

24.Thomson,M.;Al-Qattan,K.;Al-Saway,S.;Alnaqeeb,A.;Khan,I. \&Ali,M.The use of ginger as a potential anti-inflammatory \& anti- 